\title{
RAZGLEDI
}

\section{PRIPOROČILA ZA TRAJNOSTNO NAČRTOVANJE REKREACIJE NA PROSTEM V ZAVAROVANIH OBMOČJIH SLOVENIJE}

\author{
AVTORICA \\ mag. Renata Mavri \\ ERUDIO Visokošolsko središče, Litostrojska cesta 40, SI - 1000 Ljubljana, Slovenija \\ renata.mavri@gmail.com
}

DOI: $10.3986 / G V 90103$

UDK: 379.83:639.1.055.3(497.4)

COBISS: 1.01

IZVLEČEK

Priporočila za trajnostno načrtovanje rekreacije na prostem v zavarovanih območjih Slovenije $V$ prispevku so predstavljena priporočila za trajnostno načrtovanje rekreacije na prostem $v$ zavarovanih območjih Slovenije, s poudarkom na socialni nosilni zmogljivosti, na primeru Triglavskega narodnega parka in Krajinskega parka Zgornja Idrijca. Trajnostno načrtovanje rekreacije na prostem (na primeru pohodništva, gorskega kolesarjenja in vožnje š̌tirikolesniki) upošteva posebne geografske razmere za posamezne vrste rekreacije na prostem, varovalne režime različnih zavarovanih območij in zakonodajo. Zapisana izhodišča so namenjena oblikovanju priporočil za načrtovanje razvoja trajnostnih oblik rekreacije na prostem. $V$ prispevku ocenjujemo, predvsem $z$ vidika domačinov in obiskovalcev, katere oblike rekreacije na prostem so $v$ izbranih zavarovanih območjih trajnostne.

\section{KLJUČNE BESEDE}

trajnostno načrtovanje, rekreacija na prostem, socialna nosilna zmogljivost, priporočila, zavarovana območja, Triglavski narodni park, Krajinski park Zgornja Idrijca

\begin{abstract}
Recommendations for sustainable planning of outdoor recreation in the protected areas in Slovenia The article presents recommendations for sustainable planning of outdoor recreation in the protected areas with emphasis on social carrying capacity on the examples of Triglav National Park and Zgornja Idrijca Landscape Park. Sustainable planning of outdoor recreation (hiking, mountain biking and quad riding) includes specific geographical conditions that individual forms of recreation require, as well as the safety regimes of different protected areas. The starting points for the design of measures in the process of sustainable planning of outdoor recreation are presented and intended for regular monitoring and directing of outdoor recreation in the protected areas in Slovenia. In the article we assess which forms of outdoor recreation are sustainable, especially from the point of view of locals and visitors.
\end{abstract}

\section{KEY WORDS}

sustainable development, outdoor recreation, social carrying capacity, recommendations, protected areas, Triglav National Park, Zgornja Idrijca Landscape Park

Uredništvo je prispevek prejelo 12. septembra 2018. 


\section{Uvod}

Zavarovana območja v Sloveniji, poleg dobro ohranjenega naravnega okolja, predstavljajo velik ekonomski, okoljski in družbeni potencial, kar je ključnega pomena za trajnostni razvoj tako regije kot celotne države (Lampič in Mrak 2008, 145). Praviloma so poseljena, zato so v njih prisotne različne gospodarske dejavnosti kot so gozdarstvo, kmetijstvo in lov.

Zaradi obsežnih informacij, promocije zdravega načina življenja, boljše prometne dostopnosti in želje po gibanju v kakovostnem okolju se povečuje obseg preživljanja prostega časa v zavarovanih in tudi v drugih neokrnjenih območjih.

Za načrtno uveljavljanje trajnostnega razvoja turizma (in rekreacije) je ključno trajnostno načrtovanje, sprotno spremljanje/usmerjanje razvoja in upoštevanje nosilne zmogljivosti (Jurinčič 2005; 2009; 2014). V zavarovanih območjih so priporočljive trajnostne oblike rekreacije na prostem, ki vključujejo sonaravno rabo naravnih virov, hkrati pa omogočajo izboljšanje kakovosti življenja prebivalcev ter ne zmanjšujejo možnosti za življenje v sedanjosti in prihodnosti (Eagles in McCool 2002). Vse oblike rekreacije na prostem morajo biti podrejene naravovarstvenim ciljem in ne smejo biti v nasprotju s cilji zavarovanja (Guidelines ... 2000), kar velja tako za zavarovana kot nezavarovana območja.

Namen prispevka je predstaviti priporočila za trajnostno načrtovanje rekreacije na prostem $\mathrm{v}$ zavarovanih območjih (na primeru Triglavskega narodnega parka in Krajinskega parka Zgornja Idrijca), ob upoštevanju socialne nosilne zmogljivosti. Za namene raziskave smo podrobneje preučili pohodništvo, gorsko kolesarjenje in vožnjo s štirikolesniki. V raziskavi smo opredelili priporočila za trajnostno načrtovanje rekreacije na prostem. Vključujejo ukrepe, ki na izbranih zavarovanih območjih vplivajo na ravnanje domačinov; preizkusili smo jih na izbranih primerih. Pri tem smo upoštevali posebne geografske razmere, varovalne režime in zakonodajo. Namen prispevka je prikazati ugotovitve, katere oblike rekreacije na prostem so $\mathrm{v}$ zavarovanih območjih trajnostne (sprejemljive) tako $\mathrm{z}$ vidika prebivalcev zavarovanih območij kot udeležencev različnih rekreacijskih aktivnosti.

Izvajanje rekreacije na prostem v zavarovanih območjih domačinom prinaša določene koristi (delovna mesta) oziroma povzroča negativne učinke (konflikti), od česar je odvisna stopnja strinjanja prebivalcev z izvajanjem različnih oblik rekreacije (Saveriades 2000). V raziskavi se sprašujemo, ali bi se domačini strinjali z izvajanjem vseh oblik rekreacije na prostem in pod kakšnimi pogoji bi jih bili pripravljeni sprejemati v zavarovanih območjih, tudi če od njih ne bi imeli koristi (ekonomskih) in bi jim prinašale različne negativne učinke (hrup, smeti, množičnost). V Triglavskem narodnem parku smo pri oblikovanju priporočil za trajnostno načrtovanje rekreacije na prostem upoštevali zakonodajo, upravljavske smernice in varovalni režim (Zakon o Triglavskem ... 2010; Uredba ... 2016; Načrt ... 2016). Pri določanju priporočil v Krajinskem parku Zgornja Idrijca, smo upoštevali Odlok o razglasitvi krajinskega parka Zgornja Idrijca $(1993 ; 2014)$ in Razvojni načrt in strategijo trženja turizma Idrija za obdobje 2009-2015 (2009), ki pa sta že zastarela in premalo podrobna, zato pomanjkanje teh dokumentov predstavlja oviro pri razvoju. V Odloku je v 4 . členu določeno, da na celotnem območju krajinskega parka ni dovoljeno prekomerno povzročanje hrupa, kar motorna vozila in štirikolesniki zagotovo povzročajo. Po Zakonu o ohranjanju narave (2014) je vožnja z vozili na motorni ali drug lasten pogon v naravnem okolju prepovedana in to velja tudi za planinske poti (Zakon o planinskih ... 2007) in vožnjo po gozdu izven poti (Zakon o gozdovih 1993), a se kljub temu v praksi izvaja (Medmrežje 1).

\section{Teoretska izhodišča}

Svetovna in slovenska turistična strategija temeljita na trajnostnem razvoju ter usmerjata načrtovalce razvojnih politik v okoljsko, družbeno in gospodarsko ter podnebno odgovorno in trajnostno načrtovanje, tudi pri načrtovanju rekreacije na prostem. Prav tako poudarjata pomembnost izobraževanja 
za trajnostni razvoj vseh deležnikov v turizmu, ki mora postati del trajnostno naravnanih turističnih strategij (UNWTO 2016; Strategija ... 2017).

Raziskovalci pogosto $\mathrm{z}$ vidika izvajanja rekreacije na prostem ugotavljajo prepletanje nosilnih zmogljivosti, zato je pri načrtovanju treba upoštevati vse nosilne zmogljivosti in vidike razvoja (Plut in sodelavci 2008). Rezultati Manningove (1999) raziskave kažejo, da lahko izvajanje rekreacije na prostem negativno vpliva na okolje (okoljska rekreacijska nosilna zmogljivost) ter na doživljanje drugih rekreativcev (socialna rekreacijska nosilna zmogljivost) in tako nakazuje potrebo po postavitvi določenih omejitev, smernic s strani upravljavca (upravljavska rekreacijska nosilna zmogljivost).

Različne raziskave preučujejo rekreacijo na prostem $\mathrm{v}$ zavarovanih območjih in konflikte med različnimi deležniki, ki se pri tem pojavljajo, kar kaže na nujnost načrtovanja in upravljanja zavarovanih območij. Saveriades (2000) je na primeru vzhodne obale Cipra ugotovil, da obiskovanje zavarovanih območij vpliva na obiskovalce in domačine (dvosmernost) in da je treba upoštevati dva vidika razvoja: preprečevati negativne učinke turizma, ki bi jih lahko občutila lokalna skupnost (zadovoljstvo domačinov) ter hkrati skrbeti za trajnostni razvoj in kakovost turistične destinacije (zadovoljstvo obiskovalcev). Ugotavlja, da strinjanje domačinov in obiskovalcev z izvajanjem rekreacije na prostem ter njihovo "poistovetenje « $\mathrm{z}$ zavarovanim območjem prispeva k trajnostnemu razvoju. Dve raziskavi (Sterl, Wagner in Arnberger 2004 ter Burns, Arnberger in Von Ruschkowski 2010) sta na primeru narodnih parkov v Avstriji, Nemčiji in Združenih državah Amerike potrdili, da je različno pojmovanje množičnosti odvisno od različnih tipov skupin in od različnih kultur, ki se na pojav množičnosti različno odzovejo. Za različne skupine obiskovalcev so moteče predvsem velike skupine in nekatere vrste rekreacije (zlasti motorizirane) ter način in območje izvajanja (na primer navzkrižja med pohodniki in gorskimi kolesarji). Drugi dve raziskavi (Strickland-Munro, Allison in Moore 2010 ter Getzner, Jungmeier in Lange 2010) ugotavljata, da je denar lahko »ključ« za rešitev konflikta med domačini in oblastjo/upravljavcem ter da so domačini bolj strpni do obiskovalcev, če imajo od njih kakšne ekonomske koristi. Raziskavi ugotavljata, da mora biti razvoj usklajen in povezan na lokalni, regionalni in državni ravni, ker je treba za razvoj poskrbeti tudi iz finančnega vidika (hkrati delovna mesta, razvoj območja in varstvo zavarovanega območja). Arni in Khairil (2013) v svoji raziskavi v narodnih parkih na Finskem ugotavljata, da je za nadaljnji trajnostni razvoj nujno trajnostno načrtovanje in upravljanje zavarovanih območij s sodelovanjem vseh vključenih deležnikov in tudi strokovnjakov (na primer raziskovalcev, planerjev, menedžerjev, politikov).

Raziskav o socialni nosilni zmogljivosti in načrtovanju motorizirane rekreacije še ni prav veliko, vendar njihovo število narašča, saj veliko obiskovalcev zavarovana območja želi obiskati z motornim vozilom, sploh če jim to skrajša pot do ogleda naravnih in kulturnih znamenitosti in če za to obstaja ustrezna infrastruktura. Hallo in Manning (2010) ter Lawson s sodelavci (2003) so socialno nosilno zmogljivost, s pomočjo modela simulacije (analiza različnih scenarijev), ugotavljali med različnimi skupinami obiskovalcev v ameriških narodnih parkih. Raziskavi predlagata, da, ob pripravljanju prometnega načrta skozi zavarovani območji, upravljavec upošteva navade in stališča obiskovalcev zavarovanih območij, ustrezno zmanjša število motornih vozil, uredi drugačen sistem prometa (uporaba javnega sistema prometa) in sprotno spremlja in usmerja tovrstne oblike rekreacije.

V Sloveniji je socialna nosilna zmogljivost slabo raziskana, še zlasti z vidika izvajanja rekreacije na prostem $\mathrm{v}$ zavarovanih območjih, čeprav je pomembna za nadaljnje načrtovanje trajnostnega razvoja v zavarovanih območjih. Dosedanje preučevanje na tem področju je usmerjeno v navzkrižja in obremenitve različnih območij kot posledice turistične in rekreacijske dejavnosti (Plut 1999; Cigale 2004; 2012; Cigale, Lampič in Mrak 2010; Cigale in sodelavci 2014; Mrak 2009; 2011a; 2011b; 2013), in sicer primarno $\mathrm{z}$ vidika trajnostnega in skladnega regionalnega razvoja zavarovanih območij (Špes in sodelavci 2002; Plut in sodelavci 2008; Plut 2010) ter turističnega obiska zavarovanih območij (Jurinčič 2003; Jurinčič in Gosar 2003). Obenem se tovrstno preučevanje posveča tudi učinkovitemu upravljanju zavarovanih območij v Sloveniji, s poudarkom na vključevanju lokalnih skupnosti pri delovanju zavarovanih območij (Ogorelec 2002; Sovinc in Morgan 2004; Mrak in Potočnik Slavič 2005; Rodela 2007; Sovinc 2011). 
Nosilno zmogljivost in prostorsko načrtovanje trajnostnega turizma je na primeru slovenske Istre preučeval Jurinčič $(2005 ; 2009 ; 2014)$. Opredelil je prostorsko-ekološke, infrastrukturne in socio-ekonomske kazalnike nosilne zmogljivosti in ugotovil, da je za trajnostni razvoj območja nujno pravočasno in celovito prostorsko načrtovanje. Jurinčič in Balažič (2010) sta na primeru Parka Škocjanske jame s pomočjo analize nosilne zmogljivosti, ugotavljala maksimalno dnevno število obiskovalcev. Raziskava ugotavlja, da je za nadaljnji trajnostni razvoj turizma potrebna natančna razvojna strategija, izdelana v sodelovanju s turistično industrijo, občinami, državo in domačini.

\section{Metodologija}

Na podlagi pregleda literature smo predpostavljali, da je za uveljavljanje trajnostnega razvoja rekreacije na prostem $\mathrm{v}$ zavarovanih območjih nujno trajnostno načrtovanje, upoštevanje nosilne zmogljivosti, sodelovanje različnih deležnikov pri razvoju (še posebej domačinov), natančna razvojna strategija (smernice) in denar, ki je potreben za nadaljnji razvoj.

Trajnostno načrtovanje rekreacije na prostem smo opredelili kot načrtovanje trajnostnih oblik rekreacije, ki v zavarovanih območjih upoštevajo trajnostni razvoj, nosilne zmogljivosti (še posebej socialno nosilno zmogljivost) ter sprotno spremljanje in usmerjanje razvoja.

$\mathrm{V}$ prispevku obravnavamo socialno nosilno zmogljivost $\mathrm{v}$ omejenem obsegu, povezujemo jo z okoljsko in ekonomsko nosilno zmogljivostjo. Glede na tuje raziskave socialne nosilne zmogljivosti, povezane tudi z rekreacijo in turizmom $\mathrm{v}$ zavarovanih območjih (Manning 1999), smo v prispevku socialno nosilno zmogljivost opredelili kot mejo izvajanja rekreacije na prostem v zavarovanem območju, ki še lahko zagotovi trajnostno in kakovostno rekreacijo na prostem ter okolje s prav tako kakovostno rekreacijsko izkušnjo in doživetjem, ne da bi z izvajanjem negativno vplivali na domačine, obiskovalce in druge uporabnike prostora $\mathrm{v}$ zavarovanem območju. $\mathrm{V}$ prispevku obravnavamo predvsem dvosmernost socialne nosilne zmogljivosti, kar pomeni, da so socialni in kulturni vplivi rekreacije na prostem dvosmerni in da z udeležbo pri aktivnosti prihaja tako do interakcij med obiskovalci in domačini, prebivalci nekega območja, kot tudi med obiskovalci in izvajalci rekreacije nasploh (Saveriades 2000).

$\mathrm{V}$ raziskavi smo, s pomočjo predhodnega pregleda literature, opredelili priporočila za trajnostno načrtovanje rekreacije na prostem, ki smo jih nato preverili; v našem primeru v Triglavskem narodnem parku in v Krajinskem parku Zgornja Idrijca. Priporočila za trajnostno načrtovanje rekreacije vključujejo: analizo stanja, ugotavljanje socialne nosilne zmogljivosti in drugih nosilnih zmogljivosti, ugotavljanje trajnosti in sprejemljivosti rekreacije na prostem.

V prvem koraku smo izvedli analizo stanja, ki vključuje sociodemografske podatke, značilnosti obiska in izvajanje različnih oblik rekreacije na prostem. Za ugotavljanje stanja smo uporabili anketni vprašalnik, pregled geografskih razmer ter uporabo statističnih podatkov (Odar in sodelavci 2017). Za ugotavljanje socialne in drugih nosilnih zmogljivosti, smo uporabili anketni vprašalnik, ki je med drugimi vključeval vprašanja: o prisotnosti in sprejemanju različnih oblik rekreacije na prostem, o sprejemanju množične rekreacije na prostem in odnosu do nje, o potencialnih (informacija o morebitnih navzkrižjih) in dejanskih navzkrižjih pri izvajanju rekreacije na prostem, o ekonomskih koristih, o pomenu kakovostnega okolja in možnostih izvajanja rekreacije na prostem. Z njim smo ugotavljali razmerja med obiskovalci in domačini, kot tudi med obiskovalci in izvajalci rekreacije nasploh (dvosmernost). Za dodatno pojasnitev problematike smo uporabili tudi intervjuje med različnimi deležniki v zavarovanem območju. Nadalje smo prikazali, katere rekreacijske aktivnosti so trajnostne (sprejemljive) z vidika prebivalcev zavarovanega območja kot tudi udeležencev različnih rekreacijskih aktivnosti ter tudi z vidika upravljavca. Pri tem smo upoštevali usmeritve varovalnega režima in zakonodajo. Anketno raziskavo in strukturirani intervju smo uporabili, ker lahko z njima pridobimo mnenja različnih deležnikov, podatke lahko analiziramo, obdelamo in med seboj primerjamo ter z njima ocenjujemo socialno nosilno zmogljivost. 


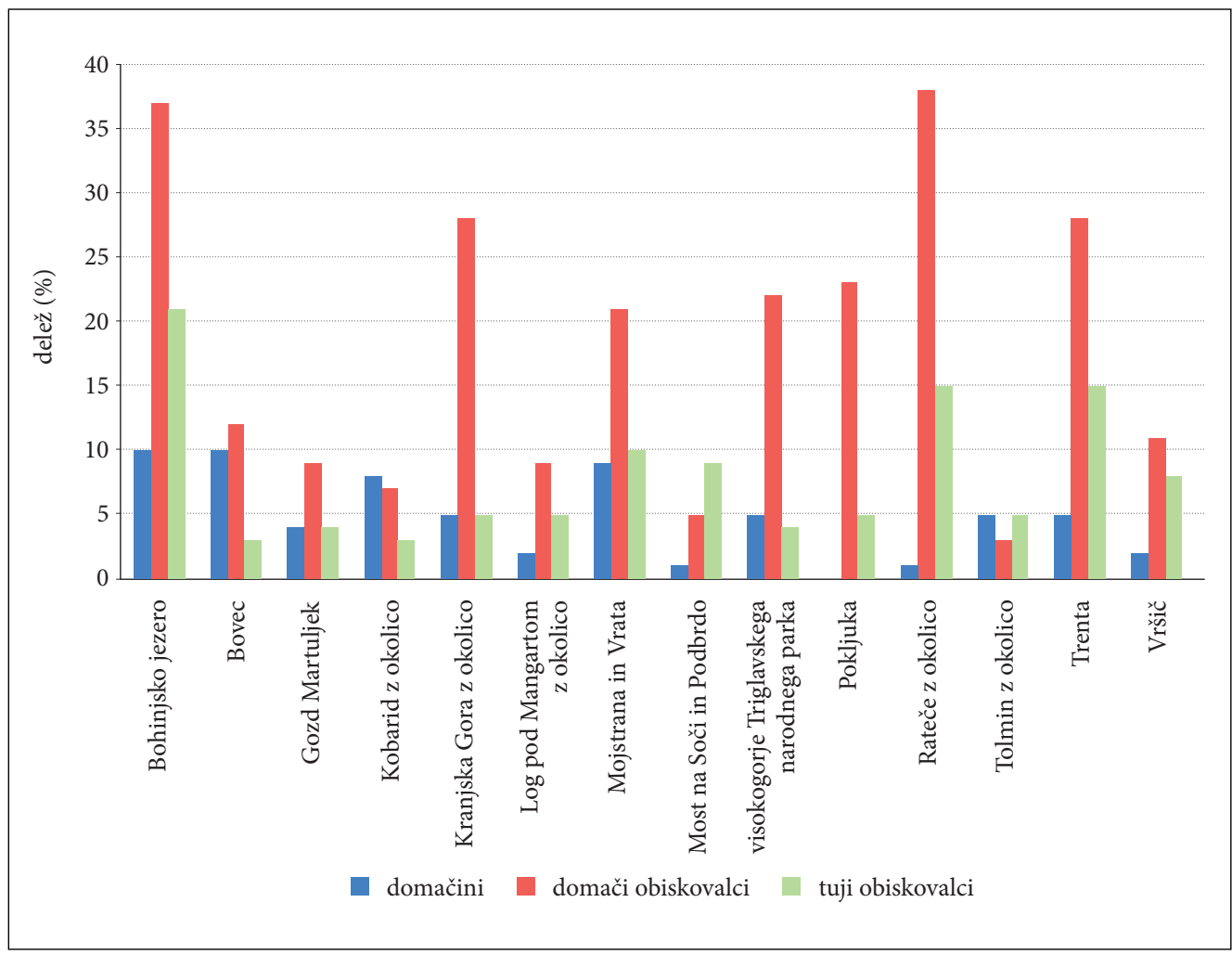

Slika 1: Število anketirancev po lokacijah v Triglavskem narodnem parku in bližnji okolici.

Preučevanje je potekalo v obdobju 2012-2013, ko smo izvedli anketno raziskavo, ki je bila namenjena domačinom in obiskovalcem zavarovanih območij. V Triglavskem narodnem parku smo anketirali 432 oseb, od tega 253 domačih in 112 tujih obiskovalcev ter 67 domačinov (slika 1). V Krajinskem parku Zgornja Idrijca smo anketirali 206 oseb, od tega 193 domačih obiskovalcev ter 13 domačinov (preglednica 1). Tujih obiskovalcev nismo anketirali, ker v krajinskem parku v času anketiranja niso bili prisotni. Anketiranje domačinov, je potekalo na več lokacijah, njihov vzorec je bil majhen. Med domačine smo šteli tiste osebe, ki živijo v zavarovanih območjih, na meji ali v njegovi neposredni bližini in imajo običajno zemljišča, ki segajo na zavarovano območje.

Preglednica 1: Število anketirancev po lokacijah v Krajinskem parku Zgornja Idrijca.

Domačini

Domači obiskovalci

Lajšt, naravno kopališče Belca

40

Idrijska Bela, gostilna Fežnar

Rake, sprehajalna pot

Strug, naravno plezališče

Skupaj

$-$

13

\section{6}

4

193 
Leta 2013 je sledil kvalitativni del raziskave, v okviru katere smo opravili poglobljene intervjuje z domačini in $\mathrm{z}$ upravljavcem zavarovanih območij. $\mathrm{Z}$ intervjuji smo nadgradili anketno raziskavo in od različnih deležnikov dobili dodatne informacije. Podatke smo analizirali in jih primerjali $z$ anketo. Intervjuvali smo upravljavce (Javni zavod Triglavski narodni park in Občina Idrija), poleg tega pa v Triglavskem narodnem parku še trinajst, v Krajinskem parku Zgornja Idrijca pa sedem domačinov.

\section{Rezultati}

V nadaljevanju prispevka navajamo priporočila za načrtovanje izbranih oblik rekreacije na prostem v zavarovanih območjih, do katerih smo prišli s pomočjo različnih metod.

Priporočamo, da je pri načrtovanju izbranih oblik rekreacije v prihodnje treba v razvoj dosledno vključevati domačine in jih spodbujati k skupnemu upravljanju zavarovanih območij. Hkrati priporočamo, da se večja pozornost nameni odnosu obiskovalcev do izvajanja rekreacije na prostem $\mathrm{v}$ zavarovanih območjih in njihovemu strinjanju, mnenju in sprejemanju različnih oblik rekreacije na prostem. Pri socialni nosilni zmogljivosti, ki smo jo preučevali, je težko predvideti, kje je meja, do katere je izvajanje določenih oblik rekreacije na prostem v zavarovanih območjih še sprejemljivo za ljudi, da ne bi prišlo do takšnega obremenjevanja, ki bi zmanjšalo njegovo nosilno zmogljivost v prihodnje. Priporočamo, da se v prihodnjih raziskavah o rekreaciji na prostem poleg socialne nosilne zmogljivosti upoštevata tudi okoljska in ekonomska nosilna zmogljivost kot del celotne nosilne zmogljivosti. V raziskavi ugotavljamo razliko v dojemanju rekreacije na prostem med obiskovalci in domačini, saj zaradi udeležbe pri rekreativni aktivnosti med njimi prihaja do različnih vplivov. Za domačine so obiskovalci sprejemljivi, če se kulturno obnašajo, upoštevajo varovalni režim in red, pa tudi če imajo od njih ekonomske koristi. Obiskovalcem se zdi najpomembneje, da imajo možnost izvajanja različnih oblik rekreacije na prostem $\mathrm{v}$ čistem, mirnem in kakovostnem okolju, zato se jim zdita pomembna red in varovalni režim v zavarovanem območju. Priporočamo, da se pri načrtovanju upošteva trajnostni razvoj rekreacije na prostem, pravila, varovalni režim ter da se ohranijo prizadevanja za kakovostno okolje, domačinom pa je treba omogočiti, da imajo od izvajanja rekreacije tudi ekonomske koristi.

Ugotavljamo, da so v zavarovanih območjih najbolj opazne in nemoteče oblike rekreacije na prostem pohodništvo, kolesarjenje ter gorsko kolesarjenje. Le vožnja s štirikolesniki poteka najpogosteje po cestah, čez prelaze in povzroča preveč hrupa. Prav tako ugotavljamo, da je pri izvajanju pohodništva še najmanj potencialnih/dejanskih navzkrižij, kar pa narašča pri kolesarjenju in gorskem kolesarjenju. Najpogostejša navzkrižja obstajajo pri motoriziranih oblikah rekreacije, in sicer pri vožnji z motorji in $\mathrm{s}$ štirikolesniki. Priporočamo, da se v zavarovanih območjih v prvi vrsti uveljavi izvajanje pohodništva, ker je najbolj trajnostna oblika rekreacije na prostem. Tudi izvajanje gorskega kolesarjenja je trajnostna oblika rekreacije na prostem, kadar se upoštevajo pravila (omejitve), varovalni režim in kulturno vedenje do ostalih obiskovalcev (pozdravljanje, prilagoditev hitrosti). Vožnja s štirikolesniki je najmanj trajnostna oblika rekreacije na prostem v zavarovanih območjih in jo ob še večji množičnosti lahko štejemo med netrajnostne rekreacije, predvsem zaradi prevelikega hrupa, zato priporočamo, da bi jo usmerili izven zavarovanih območij. Množične in motorizirane oblike rekreacije na prostem v zavarovanih območjih niso sprejemljive, zlasti če so hrupne, saj preveč motijo obiskovalce in tudi druge (lovce, gozdarje). Priporočamo, da upravljavec ustrezno pripravi prometni načrt skozi zavarovana območja, ustrezno zmanjša število motornih vozil in uredi ustrezen sistem javnega prometa.

Ugotavljamo, da varovalnega režima ne poznajo vsi dovolj dobro, zato priporočamo uvajanje predvsem mehkih ukrepov (na primer ozaveščanje, izobraževanje domačinov, usmerjanje obiskovalcev, obvestilne table) in povečani nadzor (redarji, nadzorniki). Nadalje priporočamo, naj imajo zavarovana območja pripravljene natančne in trajnostno naravnane turistične strategije, upravljavski načrt s smernicami za trajnostni razvoj rekreacije na prostem ter jasen varovalni režim. Pomembno je, da vsi deležniki dosledno upoštevajo upravljavski načrt in smernice ter uresničujejo varovalni 
režim tudi v praksi ter po potrebi izvajanje določene oblike rekreacije na prostem prej uskladijo $\mathrm{z}$ upravljavcem.

\subsection{Triglavski narodni park}

V Triglavskem narodnem parku smo anketirali 55,3\% moških; med vsemi obiskovalci je bilo največ domačih (58,6\%), starih med 26 do 35 let (29,6\%) z višjo ali visoko izobrazbo (37,5\%). Skoraj polovica anketirancev živi v naseljih z več kot 5000 prebivalci (44\%) in večina jih ne živi od turizma (90\%). Nekajkrat letno $28 \%$ anketirancev obišče zavarovano območje, v dvoje pride $26 \%$ anketiranih, $\mathrm{z}$ družino $25 \%$, za več dni 39,5\%, vendar od tega za največ $2-3$ dni (31\%) ali le za nekaj ur (36,2\%), največ poleti (76\%). Najpogosteje prihajajo zaradi izleta, ogleda ali počitnic (50\%) in zaradi možnosti rekreacije na prostem (34,6\%). Anketiranci se najpogosteje ukvarjajo s pohodništvom (91,2\%), precej manj z gorskim kolesarjenjem $(22,7 \%)$ in najmanj z vožnjo s štirikolesniki $(0,2 \%)$. Najpogosteje kot vzrok za rekreacijo na prostem navajajo lepo naravo, mirno in čisto okolje $(93,6 \%)$, bogato biološko raznolikost, kakovostno pitno vodo ter oglede naravnih in kulturnih znamenitosti $(70,1 \%)$ ter tudi možnost rekreacije na prostem $(60,4 \%)$.

Ugotovili smo, da anketiranci najbolj opazijo prisotnost pohodništva $(70,4 \%)$, nekoliko manj gorskega kolesarjenja $(58,8 \%)$ in najmanj vožnjo s štirikolesniki $(0,2 \%)$. Pri vprašanju o potencialnih navzkrižjih smo dobili odgovore, da ima z izvajanjem pohodništva potencialna navzkrižja $0,7 \%$ anketirancev (3 odgovori), z gorskim kolesarjenjem pa $10 \%$ anketirancev (43 odgovorov). Največ navzkrižij imajo anketiranci z motoriziranimi oblikami rekreacije, in sicer pri vožnji z motorji (54,6 \%) in štirikolesnikih (51,9\%). V intervjujih domačini izpostavljajo tudi dejanska navzkrižja, ki so povezana s povečanjem pohodništva v visokogorju (neurejene, preozke poti, slabe ali pomanjkljive označitve, premalo parkirišč, prevelike obremenitve na lokalnih cestah). Na pohodnike vsaj v gozdnatem delu zavarovanega območja vplivajo tudi divje zveri. Težave pa se pojavljajo tudi pri gorskih kolesarjih. Prog, ki bi bile namenjene tej rekreaciji na prostem, ni dovolj. Nekateri kolesarji so zelo nekulturni in se ne ustavijo, ko srečajo mimoidočega. $V$ intervjujih so domačini izpostavili, da so najbolj moteči množični motoristi in motorna vozila, občasno tudi štirikolesniki (čez Vršič, Log pod Mangartom). Motorizirana vozila povzročajo predvsem velik hrup, lahko pa tudi pravo okoljsko oviro, če cesta ni asfaltirana (zaprašeno rastje, slab izgled pokrajine) in če jo uporablja veliko ljudi. Vsi domačini pa kljub temu nimajo dejanskih navzkrižij pri izvajanju različnih oblik rekreacije na prostem v zavarovanem območju. Za domačine (ponudnike) so motoristi dobri gostje, sploh če se pri njih ustavijo in koristijo njihove storitve.

Med izbranimi rekreacijami na prostem je v Triglavskem narodnem parku najbolj trajnostna oblika pohodništvo. Težava je le v visokogorju zaradi množičnosti in s tem povezanimi okoljskimi problemi. Tudi gorsko kolesarjenje je trajnostna oblika rekreacije na prostem, kadar se upoštevajo pravila (omejitve) in je tudi vedenje do ostalih obiskovalcev kulturno. Vožnja s štirikolesniki ni sprejemljiva oblika rekreacije na prostem in jo štejemo med netrajnostno, predvsem zaradi prevelikega hrupa in še zlasti če domačinom ne prinaša ekonomskih koristi.

Ugotavljamo, da več kot polovica anketiranih obiskovalcev in domačinov $(53,3 \%)$ pozna varovalni režim, skoraj petina pa varovalnega režima ne pozna (19,2\%) ali ga pozna delno (27,3\%). Največ anketirancev se strinja, da naj bi varovalni režim varoval naravo, čisto okolje in skrbel za biološko raznolikost (89,6\%), omogočil obiskovalcem oddih in rekreacijo na prostem v kakovostnem okolju (70,3\%), domačinom omogočil trajnostni razvoj (62\%) in tudi varoval območje pred množičnim izvajanjem vseh oblik rekreacije na prostem (športne prireditve; 49,3\%). Pri vprašanju o prihodnjem razvoju različnih oblik rekreacije na prostem je večina anketirancev izbrala tradicionalne $(85 \%)$ in trajnostne oblike rekreacije $(75,7 \%)$ (predvsem pohodništvo, kolesarjenje), a bi dopuščali tudi gorsko kolesarjenje $(41,2 \%)$. Anketiranci si najmanj želijo množičnih $(27,3 \%)$ in motoriziranih oblik rekreacije (20,6 \%).

Slika 2: Varstveni pasovi Triglavskega narodnega parka (Varstveni ... 2018). > str. 52 


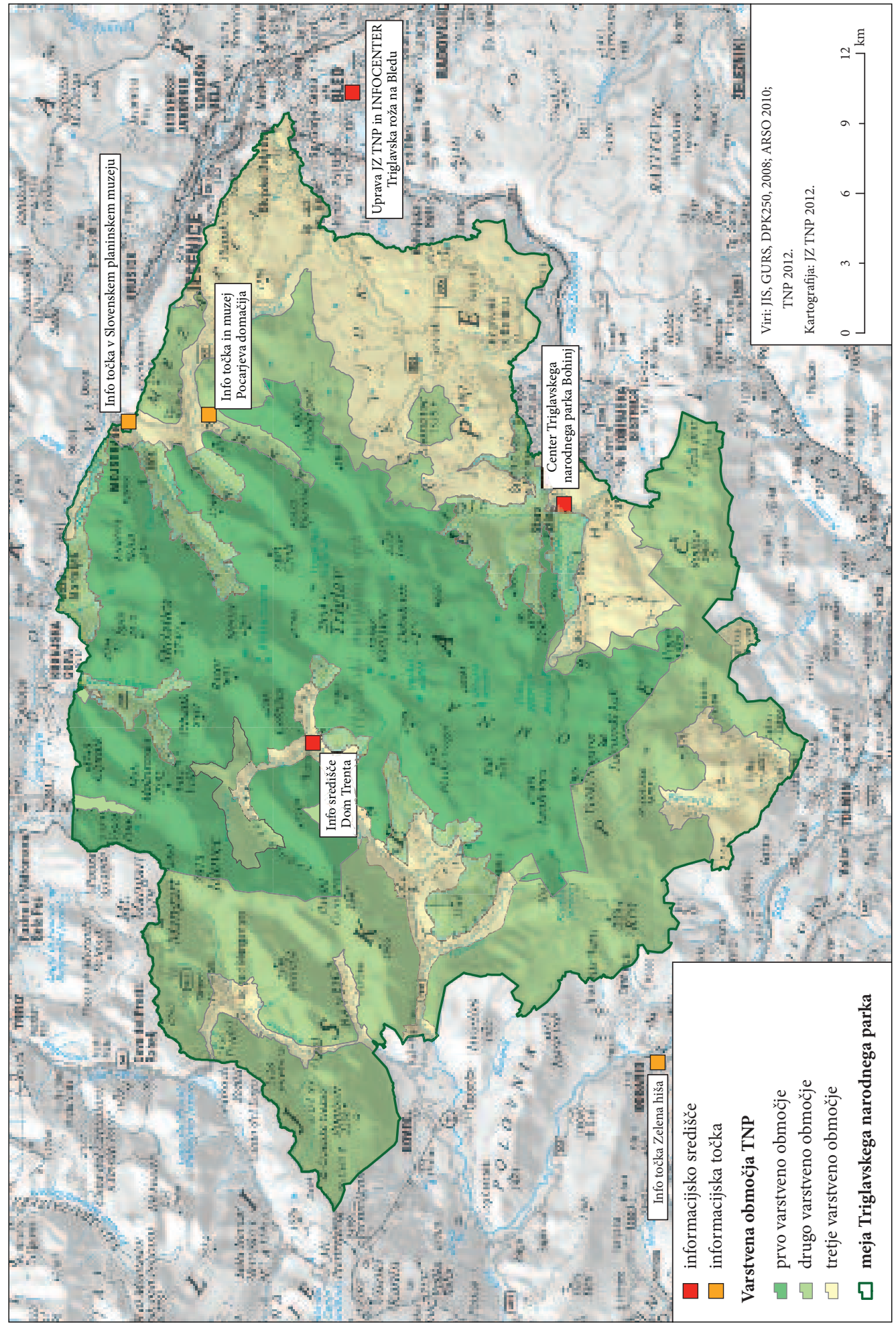


Ko smo o viziji Triglavskega narodnega parka $\mathrm{z}$ vidika izbranih oblik rekreacije na prostem povprašali še upravljavca, smo dobili odgovor, naj potekajo po ustreznih poteh, tako da ne bodo eni obiskovalci motili drugih. Hrupne oblike niso zaželene, saj preveč motijo obiskovalce. Rekreacija na prostem bo v prihodnje potekala po Uredbi o Načrtu upravljanja parka (2016), v kateri je navedeno, kako je treba določene oblike rekreacije na prostem izvajati in uskladiti z upravljavcem ter upoštevati omejitve glede na varstvene pasove (slika 2 ).

\subsection{Krajinski park Zgornja Idrijca}

V Krajinskem parku Zgornja Idrijca smo anketirali 55,8 \% moških; med vsemi obiskovalci je bilo največ domačih (93,7 \%), starih med 18 do 25 let (35,4\%), s končano srednjo šolo (47,6 \%). Skoraj polovica anketirancev živi v naseljih z več kot 5000 prebivalci $(54,9 \%)$ in večina jih ne živi od turizma (92,3\%). Nekajkrat letno $34 \%$ anketirancev in enkrat tedensko 17,5\% anketirancev (večinoma iz bližnjega mesta Idrije) obišče zavarovano območje, s skupino prijateljev pride $31,7 \%$ anketiranih, v dvoje $23,4 \%$, z družino $21,2 \%$, za nekaj ur $68,4 \%$ oziroma za en dan (27\%), največ v poletnem času $(83,5 \%)$. Najpogosteje prihajajo zaradi izleta, ogleda, oddiha, piknika $(54,1 \%), 14,5 \%$ zaradi rekreacije na prostem, $19,5 \%$ zaradi oddiha in rekreacije na prostem in 5,8 \% zaradi dela. Anketiranci se najpogosteje ukvarjajo s pohodništvom $(83,5 \%)$, kolesarjenjem in gorskim kolesarjenjem $(71,8 \%)$ ter le $0,1 \% \mathrm{z}$ vožnjo $\mathrm{s}$ štirikolesniki. Najpogosteje kot vzrok za rekreacijo na prostem navajajo lepo naravo, mirno in čisto okolje $(74,7 \%)$, možnost rekreacije na prostem $(48,1 \%)$ in bogato biološko raznolikost, kakovostno pitno vodo in oglede naravnih in kulturnih znamenitosti $(41,8 \%)$.

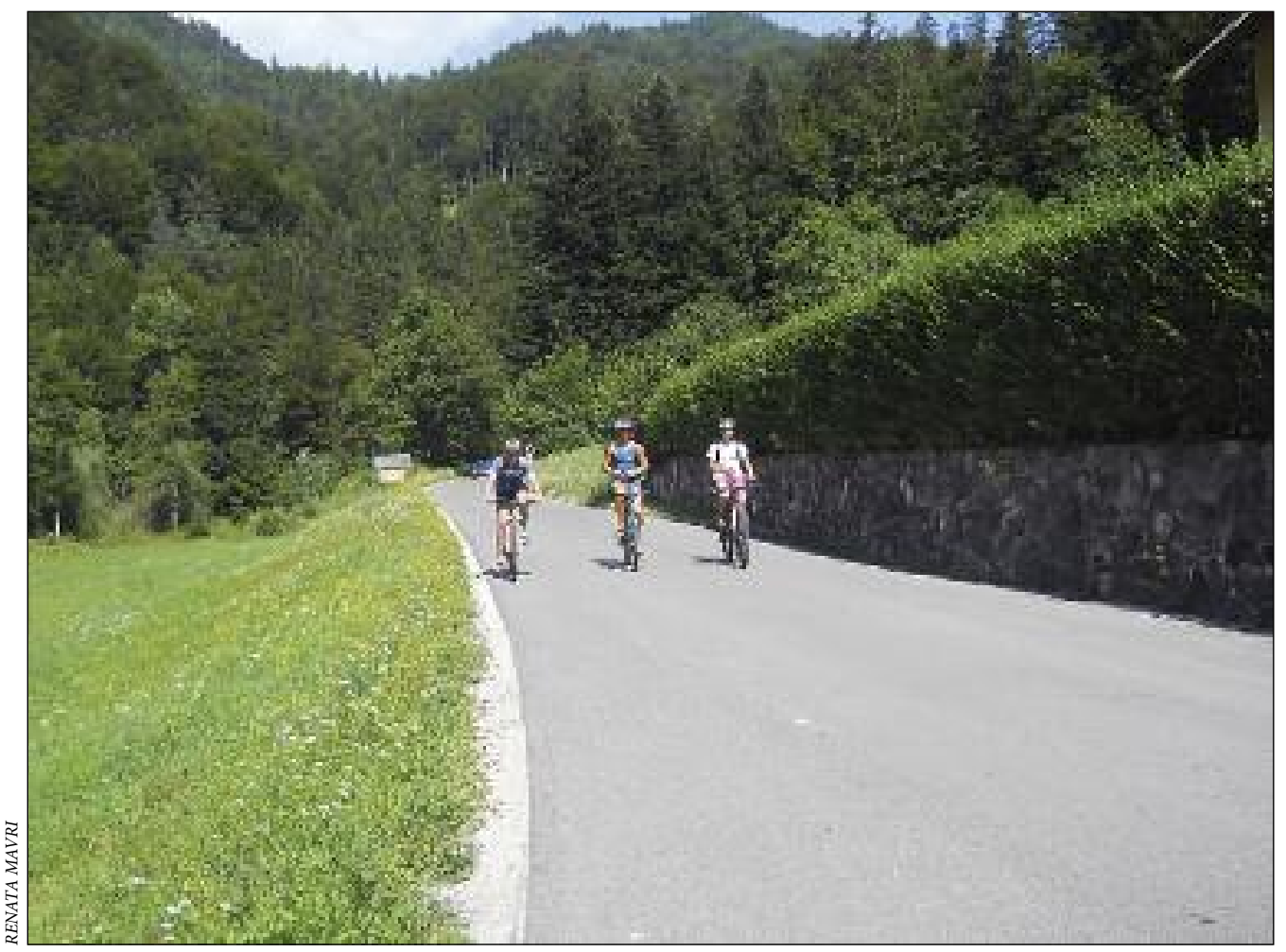

Slika 3: Kolesarji si cesto od Podroteje proti Idrijski Beli delijo z drugimi motoriziranimi vozili. 
Ugotovili smo, da anketiranci najbolj opazijo prisotnost pohodništva $(72,3 \%)$ in nekoliko manj kolesarjenja ter gorskega kolesarjenja (68,0\%). Vožnjo s štirikolesniki anketiranci opazijo v zelo majhnem deležu $(0,1 \%)$. Z izvajanjem pohodništva ima potencialna navzkrižja $4,4 \%$ anketirancev (9 odgovorov), z gorskim kolesarjenjem pa 5,8 \% anketirancev (12 odgovorov). Največ navzkrižij imajo anketiranci zaradi vožnje z motorji (57,8 \%) in štirikolesniki (56,8 \%). V komentarjih so anketiranci največkrat navedli dejanska navzkrižja, ki so povezana predvsem s srečevanjem vozil in rekreativcev na ozki vstopni poti od Podroteje proti Idrijski Beli (slika 3). Domačine motijo tudi druge stvari, ki so posledica povečanega števila rekreativcev, na primer parkiranje in kampiranje »na črno«, splošna neurejenost in nered.

Večina intervjuvancev meni, da imajo največje koristi od krajinskega parka rekreativci, ki vanj pridejo izključno zaradi rekreacije na prostem, oddiha in tudi oba gostinca. Nekateri menijo, da od krajinskega parka nima nihče velike koristi, še najmanj pa domačini, ki v njem živijo. Večina intervjuvanih domačinov se neposredno ne ukvarja $\mathrm{z}$ rekreacijo na prostem, jih pa kar nekaj premišljuje o tem (predvsem o oddajanju sob in apartmajev) in se zavedajo razvojnih možnosti. Med izbranimi oblikami rekreacije na prostem sta $\mathrm{v}$ Krajinskem parku Zgornja Idrijca najbolj trajnostni pohodništvo in gorsko kolesarjenje. Vožnja s štirikolesniki v krajinskem parku ni trajnostna oblika rekreacije na prostem (hrup).

Krajinski park še nima upravljavskega načrta, a ga pripravljajo. Občina je v okviru priprav na bodoči upravljavski načrt zavarovanega območja začela z izvajanjem projekta Nature - NIP 2011 (Lahajnar 2012). Rezultati projekta so pokazali, da se domačini, ki so doma v osrednjem, to je najbolj obremenjenem delu krajinskega parka, $\mathrm{v}$ zvezi $\mathrm{z}$ izvajanjem rekreacije na prostem $\mathrm{v}$ projekt večinoma niso vključili in tudi niso pokazali posebnega interesa za sodelovanje v prihodnje. Skoraj polovica anketiranih domačih obiskovalcev in domačinov (49,5\%) pozna varovalni režim, malo manj kot petina pa varovalnega režima ne pozna (17,5\%) ali ga pozna delno (33\%). Domači obiskovalci so najpogosteje ocenili varovalni režim v krajinskem parku kot primeren (51,3\%), za domačine pa je preblag (53,9\%). Največ anketirancev se strinja, da naj bi varovalni režim varoval naravo, čisto okolje in skrbel za biološko raznolikost (78,6\%), omogočil obiskovalcem oddih in rekreacijo na prostem v kakovostnem okolju (51,9\%), domačinom omogočil trajnostni razvoj (42,7\%) in tudi varoval območje pred množičnim izvajanjem vseh oblik rekreacije na prostem (športne prireditve; $30,1 \%$ ). Pri vprašanju o prihodnjem razvoju različnih oblik rekreacije na prostem je večina anketirancev izbrala tradicionalne $(63,6 \%)$ in trajnostne oblike rekreacije na prostem $(60,7 \%)$ (pohodništvo, kolesarjenje), a bi le petina dopuščala gorsko kolesarjenje (20,4\%). Anketiranci si najmanj želijo množičnih (12,1\%) in motoriziranih oblik rekreacije $(9,2 \%)$.

Smernic in varovalnega režima upravljavca še ni, zato domačini od vsega najbolj pogrešajo več reda, saj so večinoma mnenja, da ga pravzaprav ni in da je vse dovoljeno. Menijo, da občina v krajinski park premalo vlaga, zato tudi ni urejenega varovalnega režima. Krajinski park tudi nima nadzornika, ima zgolj občinskega redarja, ki ima manjše pristojnosti. Domačini pogrešajo večje sodelovanje in finančno podporo občine, zlasti pri začetni gradnji apartmajev in sob, želijo si tudi osnovne komunalne ureditve doline. Prav tako pogrešajo večjo strpnost pri gradnji, kar se kaže zlasti v pomanjkanju zazidljivih parcel - zaradi tega ni veliko mladih, ki bi ostali v dolini.

Upravljavec v prihodnje želi povečati nadzor in vzpostaviti večji red. V občini ceste v prihodnje ne nameravajo širili, da bi uredili kolesarsko stezo, pločnike in peš cone. Investicija bi bila namreč prevelika in se glede na kratko sezono v krajinskem parku ne bi izplačala. Na občini so razmišljali predvsem o parkirišču izven krajinskega parka, kjer bi obiskovalci svoje vozilo lahko parkirali, vanj pa bi odšli z javnim prevozom, peš ali s kolesom. Promet po krajinskem parku bodo uredili z ustrezno prometno signalizacijo, ki bo zmanjševala hitrosti in urejala parkirišča. Na tak način bi omejili hrup, manj bi bilo nevarnosti na cesti, manj onesnaževanja okolja, manj pa bi tudi motili domačine. $Z$ vidika izbranih oblik rekreacije na prostem, si občina v krajinskem parku v prihodnje prizadeva predvsem za pohodništvo in kolesarjenje ter, da bi te oblike rekreacije potekale po že obstoječih poteh (na drugi strani reke $\mathrm{v}$ Strugu). 


\section{Sklep}

Preučevanje rekreacije na prostem v izbranih zavarovanih območjih Slovenije je potrdilo, da je za uveljavljanje trajnostnega razvoja rekreacije na prostem nujen trajnostni pristop. Za Krajinski park Zgornja Idrijca je pomembna priprava nove trajnostno naravnane občinske turistične strategije, ki bo podrobneje vključevala tudi krajinski park, v povezavi s tem pa je treba uskladiti tudi Odlok o razglasitvi krajinskega parka Zgornja Idrijca (1993; 2014), pripraviti upravljavski načrt s smernicami in urediti varovalni režim.

Za prihodnji razvoj Triglavskega narodnega parka je pomembno, da bo rekreacija na prostem dosledno potekala po Uredbi o Načrtu upravljanja Triglavskega narodnega parka za obdobje 2016-2025 (2016). Nadalje potrjujemo, da je treba s posebno občutljivostjo do domačinov upoštevati socialno nosilno zmogljivost ter jih dosledno vključevati $\mathrm{v}$ razvoj in spodbujati $\mathrm{k}$ skupnemu upravljanju teh zavarovanih območij. Poleg tega je treba domačinom nameniti več finančnih spodbud in drugih pomoči (izobraževanje, urejanje infrastrukture) ter poenostaviti birokratske postopke (pri gradnji, urejanju sob) in jim omogočiti ekonomske koristi.

Raziskava potrjuje, da mora biti razvoj obeh zavarovanih območij podprt tudi s finančnega vidika, saj je treba hkrati razvijati območje, odpirati nova delovna mesta in ohranjati kakovostno okolje (državna in evropska pomoč). Za nadaljnji trajnostni razvoj rekreacije na prostem predlagamo tudi, da v razvoj vključijo strokovnjake ter k sodelovanju povabijo različne akterje zavarovanih območij, da bo razvoj usklajen in povezan na vseh ravneh (zakonodaja). Podobno so ugotavljali tudi Jurinčič in Balažič (2010), Getzner, Jungmeier in Lange (2010), Strickland-Munro, Allison in Moore (2011), Arni in Khairil (2013).

Ugotavljamo, da je naklonjenost domačinov do obiskovalcev pri izvajanju različnih oblik rekreacije na prostem odvisna od njihove kulture obnašanja, od varovalnega režima in reda, ki ga upoštevajo, pa tudi od koristi, ki jih imajo od njih. Obiskovalci si na drugi strani želijo čisto, kakovostno okolje, primerno za rekreacijo na prostem (upoštevanje okoljske in ekonomske nosilne zmogljivosti). V prihodnje je treba veliko pozornosti nameniti odnosu obiskovalcev in domačinov do izvajanja rekreacije na prostem, upoštevati dvosmernost in trajnostni razvoj (Savariades 2000).

V prispevku ugotavljamo, da sta najbolj trajnostni obliki rekreacije na prostem pohodništvo in gorsko kolesarjenje, sploh, če nista preveč množični in v kolikor se upoštevajo pravila. Treba je urediti in označiti poti (pohodniške, kolesarske), povečati nadzor ter urediti zakonodajo. Vožnja s štirikolesniki ni trajnostna oblika rekreacije na prostem v zavarovanih območjih, predvsem zaradi prevelikega hrupa in če domačinom ne prinaša ekonomskih koristi. Treba je pripraviti prometni načrt in uvesti javni promet skozi zavarovani območji. Za prihodnji razvoj je potrebno sprotno spremljanje in usmerjanje razvoja rekreacije na prostem in izobraževanje za trajnostni razvoj vseh deležnikov v turizmu, kot usmerja tudi Strategija trajnostne rasti slovenskega turizma 2017-2021 (2017).

\section{Viri in literatura}

Arni, A. G., Khairil, W. A. 2013: Promoting collaboration between local community and park management towards sustainable outdoor recreation. Procedia-Social and Behavioral Sciences 91. DOI: https://doi.org/10.1016/j.sbspro.2013.08.401

Burns, R., Arnberger, A., Von Ruschkowski, E. 2010: Social carrying Capacitiy Challenges in parks, forests, and protected areas. International Journal of Sociology 40-3. DOI: https://doi.org/10.2753/ IJS0020-7659400302

Cigale, D. 2004: Posledična navzkrižja in obremenitve slovenskega alpskega sveta zaradi turistične in rekreativne dejavnosti. Doktorsko delo, Filozofska fakulteta Univerze v Ljubljani. Ljubljana.

Cigale, D. 2012: Development patterns of Slovene tourist destinations. Geografski vestnik 84-1. 
Cigale, D., Lampič, B., Mrak, I. 2010: Turistični obisk in zavarovana območja, primer Triglavskega narodnega parka. Dela 33. DOI: https://doi.org/10.4312/dela.33.75-96

Cigale, D., Lampič, B., Potočnik Slavič, I., Repe, B. 2014: Geografsko raziskovanje turizma in rekreacije v Sloveniji. GeograFF 15. Ljubljana.

Eagles, P. F. J., McCool, S. F. 2002: Tourism in National Parks and Protected Areas: Planning and Managament. Waterloo.

Getzner, M., Jungmeier, M., Lange, S. 2010: People, Parks and Money - Stakeholder Involvement and Regional Development: A Manual for Protected Areas. Klagenfurt.

Guidelines for Protected Area Management Categories: Interpretation and Application of the Protected Area Management Categories in Europe. Grafenau, 2000.

Hallo, J., Manning, R. E. 2010: Analysis of social carrying capacity of national park scenic road. International Journal of Sustainable Transportation 4-2. DOI: https://doi.org/10.1080/15568310802438940

Jurinčič, I. 2003: Načrtovanje in nadzor turističnega obiska v zavarovanih območjih s pomočjo analize nosilne zmogljivosti. Zavarovana območja in njihov pomen za turizem. Koper.

Jurinčič, I. 2005: Carrying capacity assessment of Slovene Istria for tourism. Sustainable Development and Planning II. Southampton.

Jurinčič, I. 2009: Nosilna zmogljivost Slovenske Istre za turizem. Portorož.

Jurinčič, I. 2014: Prostorsko načrtovanje trajnostnega turizma s pomočjo analize nosilne zmogljivosti. Trajnostni razvoj turističnih destinacij alpsko-jadranskega prostora. Koper.

Jurinčič, I., Balažič, G. 2010: Determining the carrying capacity of the Škocjan caves Park for the implementation of sustainable visitor management. Turizem in kakovost življenja. Portorož.

Jurinčič, I., Gosar, A. 2003: Sustainable tourism in the Alpe-Adria region: reality and goals. Dela 19.

Lahajnar, D. 2012: Izhodišča za program dejavnosti: projekt Nature - NIP 2011. Krajinski park Zgornja Idrijca. Idrija.

Lampič, B., Mrak, I. 2008: Vrednote, vrednosti in razvojni potenciali območij varovanja. Dela 29. DOI: https://doi.org/10.4312/dela.29.145-159

Lawson, S., Manning, R. E., Valliere, W. A., Wang, B. 2003: Proactive monitoring and adaptive managament of social carrying capacity in Arches National Park: an application of computer simulation modeling. Journal of Environmental Managament 68-3. DOI: https://doi.org/10.1016/S03014797(03)00094-X

Manning, R. E. 1999: Studies in outdoor recreation. Search and Research for Satisfaction. Corvallis.

Medmrežje 1: https://www.youtube.com/watch?v=WKL9ykAd_Rw (14.9.2018).

Mrak, I. 2009: Sonaravni razvoj turizma in rekreacije v visokogorju. Doktorsko delo, Filozofska fakulteta Univerze v Ljubljani. Ljubljana.

Mrak, I. 2011a: High mountain areas and their resilience to tourism development. GeograFF 11. Ljubljana.

Mrak, I. 2011b: Načrtovanje sonaravnega razvoja pustolovske rekreacije v zavarovanih območjih Slovenije - primer pohodništva. Razvoj zavarovanih območij v Sloveniji, Regionalni razvoj 3. Ljubljana.

Mrak, I. 2013: Po planinskih poteh. Problematika voženj v naravnem okolju: Imamo rešitve, toda ali imamo voljo? Ljubljana.

Mrak, I., Potočnik Slavič, I. 2005: Living in a protected area: Adjusting to restrictions or development challenge? International Scientific Conference Mountain Without Borders. Tarvisio.

Načrt upravljanja Triglavskega narodnega parka 2016-2025. Javni zavod Triglavski narodni park. Bled, 2016.

Odar, M., Marolt, M., Krek, A., Mrak, I. 2017: Turistični obisk biosfernega območja Julijskih Alp. Analiza vprašalnika o obiskovanju Triglavskega narodnega parka 2016. Javni zavod Triglavski narodni park. Bled.

Odlok o razglasitvi krajinskega parka Zgornja Idrijca. Uradni list Republike Slovenije 11/1993. Ljubljana.

Odlok o spremembah in dopolnitvah Odloka o razglasitvi krajinskega parka Zgornja Idrijca. Uradni list Republike Slovenije 36/2014. Ljubljana. 
Ogorelec, B. 2002: Establishing a nature park: lessons learnt. ALPE Kulture v prostoru in trajnostna prihodnost. Bolzano.

Plut, D. 1999: Pokrajinski vidiki sonaravnega razvoja zavarovanih območij slovenskih Alp. Dela 13. DOI: https://doi.org/10.4312/dela.13.103-113

Plut, D. 2010: Geografija sonaravnega razvoja. Ljubljana.

Plut, D., Cigale, D., Lampič, B., Mrak, I. 2008: Trajnostni razvoj varovanih območij, celostni pristop in aktivna vloga države, trajnostno gospodarjenje v varovanih območjih $\mathrm{z}$ vidika doseganja skladnejšega regionalnega razvoja: končno poročilo. Filozofska fakulteta Univerze v Ljubljani. Ljubljana.

Razvojni načrt in strategija trženja turizma Idrija za obdobje 2009-2015. Občina Idrija. Idrija, 2009.

Rodela, R. 2007: Integrated rural development: protected areas and their potential for social learning. Tourism Management 21.

Saveriades, A. 2000: Establishing the social tourism carrying capacity for the tourist resort of the east coast of the Republic of Cyprus. Tourism Management 21-2. DOI: https://doi.org/10.1016/S02615177(99)00044-8

Sovinc, A. 2011: Oblikovanje modela za učinkovito upravljanje zavarovanih območij narave. Doktorsko delo, Fakulteta za humanistične študije Univerze na Primorskem. Koper.

Sovinc, A., Morgan, B. 2004: Turizem v zavarovanih območjih, priložnost in grožnja. Zavarovana območja in njihov pomen za turizem. Koper.

Sterl, P., Wagner, S., Arnberger, A. 2004: Social carrying of canoeists in Austria's Danube Floodplains National park. Recreation and Conservation Planning. Wien.

Strategija trajnostne rasti slovenskega turizma 2017-2021. Slovenska turistična organizacija. Ljubljana, 2017.

Strickland-Munro, J. K., Allison, H. E., Moore, S. A. 2010: Using resilience concepts to investigate the impacts of protected area tourism on communities. Annals of Tourism Research 37-2. DOI: https://doi.org/ 10.1016/j.annals.2009.11.001

Špes, M., Cigale, D., Lampič, B., Natek, K., Plut, D., Smrekar, A. 2002: Študija ranljivosti okolja: metodologija in aplikacija. Geographica Slovenica 35, 1-2. Ljubljana.

UNWTO 2016: The Guidebook "Sustainable Tourism for Development". Brussels.

Uredba o Načrtu upravljanja Triglavskega narodnega parka za obdobje 2016-2025. Uradni list Republike Slovenije 34/2016. Ljubljana.

Varstveni pasovi Triglavskega narodnega parka. Javni zavod Triglavski narodni park. Bled, 2018.

Zakon o gozdovih. Uradni list Republike Slovenije 30/1993. Ljubljana.

Zakon o planinskih poteh. Uradni list Republike Slovenije 61/2007. Ljubljana.

Zakon o spremembah in dopolnitvah Zakona o ohranjanju narave. Uradni list Republike Slovenije 46/2014. Ljubljana.

Zakon o Triglavskem narodnem parku. Uradni list Republike Slovenije 52/2010. Ljubljana.

\section{Summary: Recommendations for sustainable planning of outdoor recreation in the protected areas in Slovenia}

(translated by Tea Karlo)

The study of outdoor recreation in protected areas (Triglav National Park and Zgornja Idrijca Landscape Park) of Slovenia has confirmed that in these areas, a sustainable approach is needed in order to promote the sustainable development.

The article confirms that for further sustainable development, timely sustainable planning of outdoor recreation and preparation of precise development guidelines are needed, as well as appropriate development strategies that would be made with the participation of all stakeholders in the protected area (especially the locals living in the protected area). The undeveloped guidelines and the management 
plan present an obstacle especially for the sustainable development of the Zgornja Idrijca Landscape Park, which points to the lack of interest by the manager (Municipality of Idrija) for more serious management and further development of the landscape park. The Municipality of Idrija is aware that the landscape park could be a development opportunity for the locals, however, it does not offer enough financial incentives and other assistance (education, infrastructure management when the landscape park does not have any visitors, etc.), since the officials are of the opinion that larger investments in the landscape park do not pay off. We find that the locals want greater cooperation and involvement in the management in both protected areas as they see a development opportunity and a future vision in them, which makes communication and cooperation between the locals and the managers very important in regards with further sustainable development. Our example confirms that the development of protected areas must be supported from the financial point of view (workplaces and nature protection simultaneously), and that sustainable development of outdoor recreation in protected areas is possible, as long as there are clear and solid links between the environment, the locals and the manager, which is why the management of protected areas in the future must, more than now, be based on dialogues and social knowledge. Different problems, negative effects and conflicts must be tackled with by active co-operation and consensus between the manager and the locals. Other stakeholders of protected areas (visitors, development and tourist agencies), as well as various experts (planners, researchers, managers, politicians) should be invited to participate in the development, so that the development would be coordinated and connected to the local (the locals), regional (the manager) and state level (the legislation). Jurinčič and Balažič (2010), Getzner, Jungmeier and Lange (2010), Strickland-Munro, Allison and Moore (2011), Arni and Khairil (2013) came to similar conclusions.

In the future, a lot of attention should be paid to the attitude of the visitors and the locals in regards to outdoor recreation, to overseeing their agreement and opinion on the acceptance of various forms of outdoor recreation, to taking into account the bi-directionality, to striving for "mutual satisfaction" between the locals/visitors and to pursuing sustainable development (Savariades 2000). We find that for the locals, the acceptability of visitors regarding the implementation of various forms of outdoor recreation depends on the visitors' culture of behaviour, on the protection regime and the order the visitors comply with (e.g., illegal camping, parking outside the intended parking lots, walking off the pathways, failure to observe speed restrictions), as well as on the benefits (especially economic) that they have from the visitors. At the same time the visitors desire a clean, quality environment, appropriate for outdoor recreation, and above all, order so as to preserve the environment.

The article confirms that not every form of outdoor recreation carried out in protected areas is sustainable. The most sustainable and acceptable form of outdoor recreation in both protected areas is outdoor hiking, except in certain cases, such as summer weekends and holidays. The control should be increased, the limits in the most overburdened areas and regarding the time set, while the hikers should be directed on their way (especially in the Zgornja Idrijca Landscape Park). Cycling and mountain biking are also sustainable forms of outdoor recreation, especially if there is not too much mass and the rules are observed (restrictions), as well as appropriate cultural behaviour towards other visitors and the locals applied. The paths should be organized and marked, precise guidelines (legislation) set, which will clearly define restrictions and prohibitions, especially for mountain biking, control increased and more order established. Driving with quads is not an acceptable form of outdoor recreation in protected areas and is considered as unsustainable, mainly due to excessive noise, and especially if it does not mean additional economic benefits for the local people; it should be limited or directed outside the protected areas, where polygons should be arranged. For future sustainable development a lot of attention should be paid to motorized forms of recreation in protected areas, which should be closely monitored and directed. As the researches on motorized forms of recreation (Lawson et al. 2003; Hallo and Manning 2010) suggest, the manager should, when preparing a roadmap through protected areas, take into account the habits and views of the visitors in the protected area and appropriately reduce the number of motor vehicles or arrange a different traffic system (e.g. mandatory use of pub- 
lic transport system by bus, parking outside the protected area), in order to achieve greater tolerance among the park visitors on a daily basis, especially during the summer season.

We suggest the introduction of mostly soft measures (awareness raising, education of locals, visitor directing, cooperation, etc.), increased control, additional path management and more order, prevention of mass - traffic calming, regulation of traffic signalization and introduction of joint transport to the landscape park. Preparation of precise and sustainably oriented tourism strategy is important for the Zgornja Idrijca Landscape Park, in regards to which a Decree on the proclamation of the Zgornja Idrijca Landscape Park (Odlok ... 1993; 2014) should be harmonized, a management plan with precise guidelines for the sustainable development of outdoor recreation prepared (the limits of excessive noise and also the methods of measurement more precisely defined), and the protective regime taken into account (increased control and more order). In the Triglav National Park, the outdoor recreation should be carried out consistently in accordance with the Decree on the Management Plan (Uredba ... 2016), which states how certain types of outdoor recreation should be implemented and coordinated with the manager. Both protected areas require regular monitoring and directing of the development of outdoor recreation and the education on the sustainable development of all stakeholders in tourism, as the Strategy for Sustainable Growth of Slovenian Tourism 2017-2021 (Strategija ... 2017) instructs. 